Research Article

\title{
Impact of Cold-Rolling and Heat Treatment on Mechanical Properties of Dual-Phase Treated Low Carbon Steel
}

\author{
Le Van Long, ${ }^{1}$ Dinh Van Hien $\mathbb{D}^{2},{ }^{2}$ Nguyen Truong Thanh $\mathbb{D}^{2},{ }^{2}$ Nguyen Chi Tho, ${ }^{3}$ \\ and Van Thom Do iD ${ }^{4}$ \\ ${ }^{1}$ Institute of Technology, General Department of Defense Industry, Hanoi, Vietnam \\ ${ }^{2}$ Academy of Military Science and Technology, Hanoi, Vietnam \\ ${ }^{3}$ Institute of Techniques for Special Engineering, Le Quy Don Technical University, Hanoi, Vietnam \\ ${ }^{4}$ Faculty of Mechanical Engineering, Le Quy Don Technical University, Hanoi, Vietnam \\ Correspondence should be addressed to Dinh Van Hien; vanhiencompany221182@gmail.com and Van Thom Do; \\ thom.dovan.mta@gmail.com
}

Received 6 November 2019; Revised 6 January 2020; Accepted 21 January 2020; Published 25 February 2020

Academic Editor: Pavel Lejcek

Copyright (c) 2020 Le Van Long et al. This is an open access article distributed under the Creative Commons Attribution License, which permits unrestricted use, distribution, and reproduction in any medium, provided the original work is properly cited.

\begin{abstract}
The low carbon steel has good ductility that is favorable for forming process, but its low strength leads to limiting their application for forced structures. This paper studied improving strength of low-carbon steel via rolling deformation and dual-phase treatment. The results showed that the dual-phase treated steel had a combination of high strength and good ductility; its tensile ultimate strength reached $740 \mathrm{MPa}$ with elongation at fracture of over $15 \%$, while that of the cold-rolled steel only reached $700 \mathrm{MPa}$ with elongation at fracture of under 3\%. Based on the obtained results, relationships between mechanical properties and dual-phase processing parameters were established to help users choose suitable-processing parameters according to requirements of products.
\end{abstract}

\section{Introduction}

The low carbon steels were classically structural steels, which are studied, produced, and applied to industry for a long time, but they are still continuously being investigated to improve strength and ductility for strictly required applications such as increasing strength of car members and pressure vessels. According to the common material law, it is possible to impact on chemical composition or microstructure to change mechanical properties of materials. Recently, the trend of impacting on microstructure, using unique microstructural effects to improve strength and balance strength and ductility of low carbon steels, has been investigated widely, including the use of the dual-phase microstructural effect. The microstructure of these steels consists of a soft matrix of ferrite and particles of dispersedhard martensite. The mechanical properties of dual-phase steels depend on properties of phases, volume fraction, grain size, and shape of phases.
There were many studies on the influence of volume fraction of phases on mechanical behavior of the dual-phase steels. Marder [1] reported that the higher the volume fraction of martensite is, the higher the tensile strength will be, and the ductility will be sacrificed; hence, the combination of strength and ductility will be more balanced. These also agreed with the studies of Mazinani and Poole [2] and Mazaheri et al. [3]. Fonstein [4] and Rana and Singh [5] summarized hundreds of dual-phase steel-related articles and showed that ferrite phase is very ductile and absorbs strain around martensite grains enabling a good elongation. Most of the studies summarized in Fonstein [4] and Rana and Singh [5] showed that the increase in volume fraction of martensite leads to an increase in tensile strength and the reduction in elongation. Moreover, the finer dual-phase microstructure leads to the increase in tensile strength and work hardening rate $(\mathrm{d} \sigma / \mathrm{d} \varepsilon)$.

Burford et al. [6] investigated the influence of grain size of ferrite on mechanical properties of the dual-phase $0.08 \mathrm{C}$ $1.45 \mathrm{Mn}-0.2 \mathrm{Si}$ steel, showing that the microstructure with the 
finer ferrite grains had the higher tensile strength, but the yield strength was mostly constant. Recently, Alibeyki et al. [7] studied the production of the fine-grain dual-phase steel with the chemical composition of $0.12 \mathrm{C}-1.1 \mathrm{Mn}-0.16 \mathrm{Si}$ by using a combination of heat treatment cycles and coldrolling; as a result, the finer the dual-phase microstructure, the better the tensile strength, and the better the balance of strength and ductility.

Mazaheri et al. [3] processed the cold-rolled $0.17 \mathrm{C}-0.4 \mathrm{Si}-$ $1.15 \mathrm{Mn}-0.95 \mathrm{Cr}$ steel of $50 \%$ and $80 \%$ in thickness reduction to the dual-phase microstructure at $700^{\circ} \mathrm{C} / 6-8-10-12 \mathrm{~min}-$ utes and found that the dual-phase treated steel had more prominent strength than the as-received steel. For the dualphase treated steel, increasing the holding time makes volume fraction of martensite increase, which leads to an increase in tensile strength and makes the elongation sacrificed. In another study, Terada et al. [8] created two types of martensite microstructures for the $0.087 \mathrm{C}-0.79 \mathrm{Si}-1.77 \mathrm{Mn}$; one of them was networked martensite by using intercritical annealing and the other was islanded martensite by austenitizing and cooling to intercritical annealing temperature, then all of them were quenched in water. The cored result was that the networked martensite made the steel have a better combination of strength and ductility compared to the isolated martensite because the partition of strain between phases in networked martensite microstructure was less.

Hüseyin et al. [9] studied the effect of intercritical annealing temperature and cooling rate on mechanical properties of commercial low carbon alloy steel and showed that the dual-phase process has brought about the excess of strength and the better balance of strength and ductility. Nouroozi et al. [10] processed a $0.035 \mathrm{C}-0.268 \mathrm{Mn}-0.035 \mathrm{Si}$ low carbon steel to a dual-phase microstructure; as a result, the dual-phase treated steel had a tensile strength level of $400 \mathrm{MPa}$ compared to its normalized steel with a tensile strength level of $300 \mathrm{MPa}$. They also used the dual-phase treatment for the cold-rolled steel of $50 \%$ in thickness reduction; as a result, the tensile strength reached $600 \mathrm{MPa}$. The chief reason of the result was that the change of microstructure from ferrite and pearlite to ferrite and harder martensite, as well as refinement of microstructure, leads to the increase in the tensile strength. In a recent study, Bayram et al. [11] reported a same result of improving the strength of $0.1^{\circ} \mathrm{C}$ low carbon steel by using the dual-phase process.

However, there have been only a few studies on applying the dual-phase process for low carbon steels, as well as determining effects of deformation and heat treatment on mechanical properties of dual-phase treated low carbon steels and especially, finding out laws on the relationship between deformation and heat treatment with their mechanical properties.

In order to find out laws of relationship between processing parameters and mechanical properties of dual-phase steel, Kim et al. [12] utilized the orthogonal design method and analysis of variance (ANOVA); as a result, not just the laws of relationship between processing parameters and mechanical properties were explored but the degrees of the effect of processing parameters on mechanical properties were detected. In another study, Hien et al. [13] used the full factorial design of experiment to evaluate the effect of three processing parameters on mechanical properties of TRIP steel and they established the regression functions expressing the relationships between processing parameters and mechanical properties, and found the processing parameter regions for optimizing mechanical properties of the steel. Clearly, the design of the experiment is a useful method for experimental studies.

From the actual requirement of improving the strength of low carbon steels and the above analysis, in this study, we will focus on the effect of cold-rolling and dual-phase treatment on mechanical properties of low carbon steel by using design of experiments.

\section{Experiment}

Casted-steel bars were melted in a vacuum induction furnace VIM300, which is having the chemical composition shown in Table 1. The critical temperatures were measured by a dilatometer at a heating rate of $5 \mathrm{~K} \cdot \mathrm{min}-{ }^{1}$ on a cylindrical specimen in a NETZSCH DIL 204 PC instrument (Figure 1).

These steel bars were forged with a forged ratio of 12 , hot-rolled to a thickness reduction of $12 \mathrm{~mm}$, and then were cold-rolled to different thickness reductions from 0 to $90 \%$ on a duo-rolling mill with an axis diameter of $120 \mathrm{~mm}$. A group of cold-rolled steel samples were used for measuring the mechanical properties. Other steel samples with thickness reductions of 50,60, and 70\% were quenched in water after intercritical annealing in a resistance furnace at different temperatures and holding at a constant time of 20 minutes to determine the effect of rolling thickness reduction and intercritical annealing on mechanical properties of the steel, simultaneously, on grain size and volume fraction of ferrite and martensite. The processing schedule is shown in Figure 2.

The full factorial plan was utilized for designing the experiment of the dual-phase treated steel. A total number of 9 experiments were carried out and the two factors investigated are thickness reduction in rolling $\left(\varepsilon_{\mathrm{TR}}\right)$ and intercritical annealing temperature $\left(T_{\mathrm{IA}}\right)$, in which the investigated thickness reductions, $\varepsilon_{T R}$, was 50,60 , and $70 \%$, and the used intercritical annealing temperature was 740,785 , and $830^{\circ} \mathrm{C}$.

The steel samples for investigating the microstructure were roughed, polished, and then etched: the cold-rolled steel samples were etched by Nital $2 \%\left(2 \% \mathrm{HNO}_{3}\right.$ in $100 \mathrm{ml}$ alcohol) and of dual-phase treated steel samples were etched via two steps, the first by Nital solution and then by $2 \%$ $\mathrm{Na}_{2} \mathrm{SO}_{4}$ in water. Finally, they were observed in an optical microscope AXIO-A2M.

The volume fraction of ferrite and martensite was measured by using the point counting method according to the ASTM E562 standard. The carbon content in martensite was determined by using the equation, $C_{M}=C_{0} / f_{M}$, since the dual-phase microstructure includes two phases of ferrite and martensite and the carbon concentration in ferrite is very tiny, so carbon is almost concentrated in martensite.

The average grain sizes of ferrite and martensite were estimated by using the grain counting method according to the ASTM E112 standard. 
TABle 1: Chemical composition (wt\%) and $A_{c 1}$ and $A_{c 3}$ temperature of the steel.

\begin{tabular}{lccccccccccc}
\hline $\mathrm{C}$ & $\mathrm{Si}$ & $\mathrm{Mn}$ & $\mathrm{P}$ & $\mathrm{S}$ & $\mathrm{Cu}$ & $\mathrm{Ni}$ & $\mathrm{Cr}$ & $\mathrm{Al}$ & $\mathrm{Mo}$ & $A_{c 1}\left({ }^{\circ} \mathrm{C}\right)$ & $A_{c 3}\left({ }^{\circ} \mathrm{C}\right)$ \\
\hline 0.112 & 0.266 & 0.487 & 0.012 & 0.011 & 0.119 & 0.159 & 0.219 & 0.045 & 0.018 & 702,7 & 872,1 \\
\hline
\end{tabular}

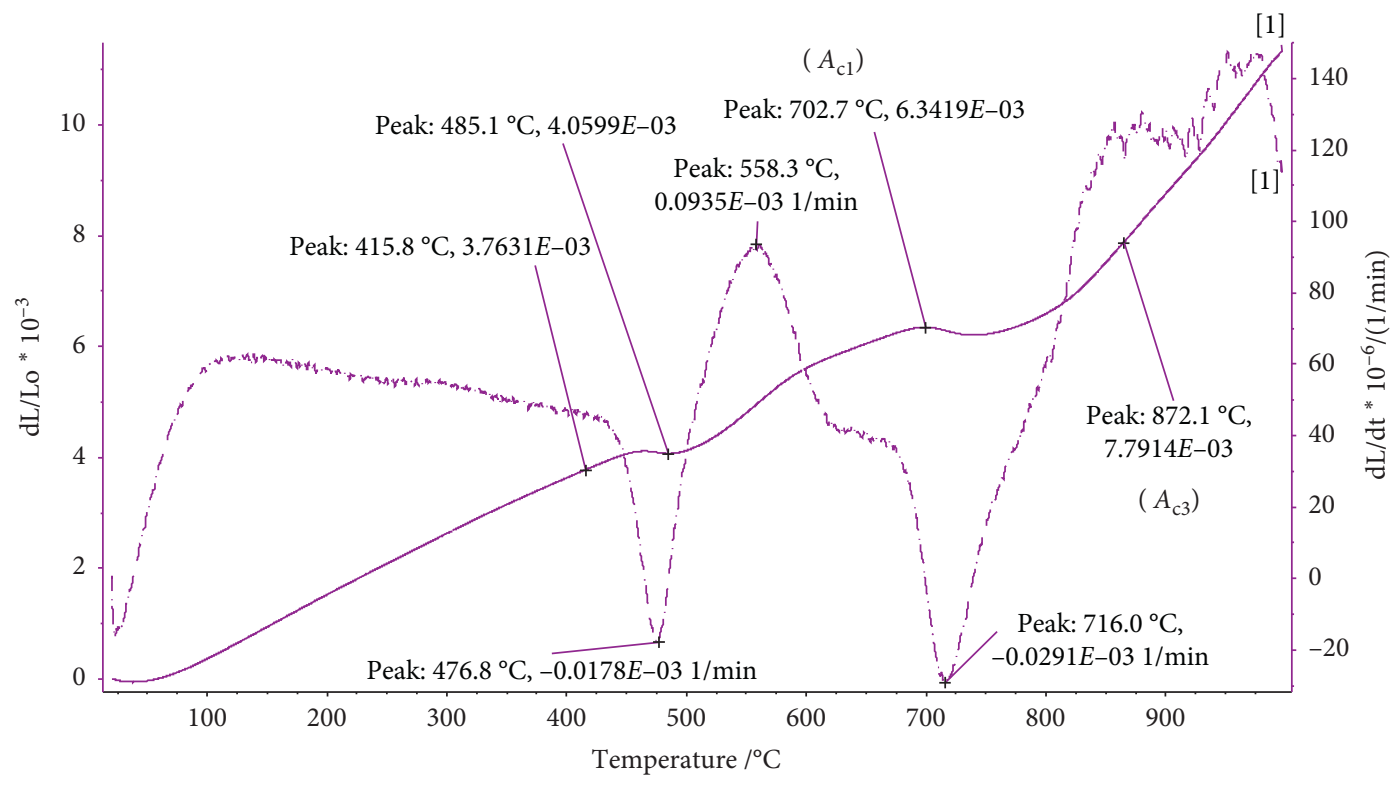

[1DIL sample.sl4

$-\mathrm{dL}$

$\cdot-\cdot \mathrm{dL} / \mathrm{dt}$

FIgUre 1: Dilatation of the steel for determining $A_{\mathrm{c} 1}$ and $A_{\mathrm{c} 3}$.

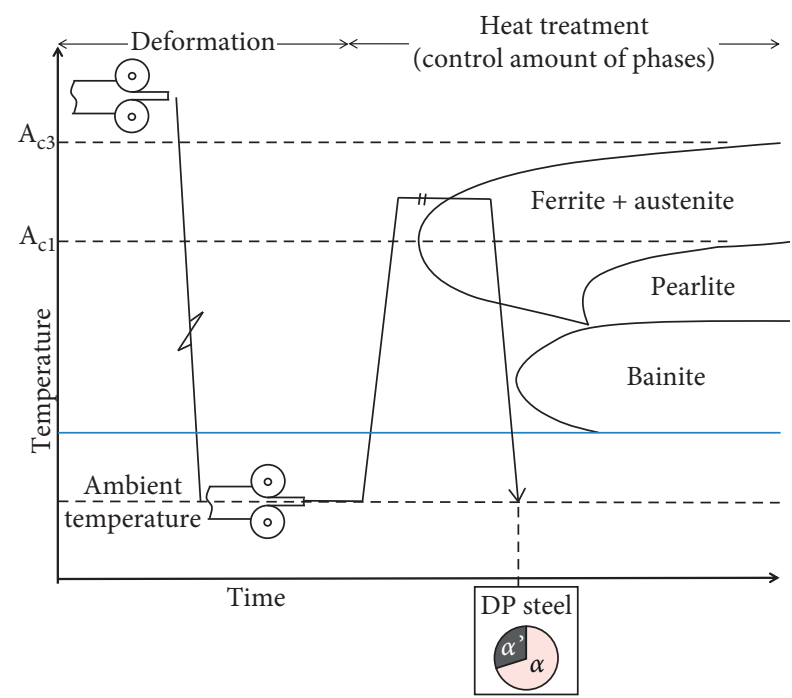

Figure 2: Process schedule used to achieve the dual-phase microstructure.

The mechanical properties of the steel samples in different conditions were measured by using the ASTM E8 standard on a tensile testing equipment TT-HW2-1000 with the displacement speed of $10 \mathrm{~mm} / \mathrm{min}$. The dimension of the tensile test sample is in Figure 3.

The measurement results of mechanical properties and microstructural characterization are shown in Tables 2 and 3.

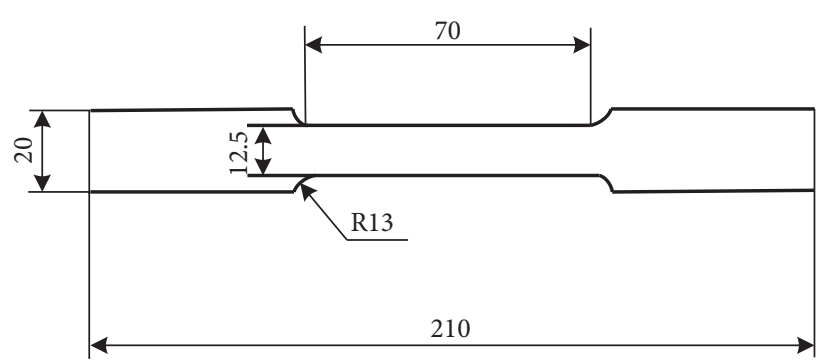

Figure 3: Dimension of the tensile test sample.

TABLE 2: Mechanical properties of the cold-rolled steel.

\begin{tabular}{lccccc}
\hline No. & $\varepsilon_{T R}(\%)$ & $R_{m}(\mathrm{MPa})$ & $R_{p}(\mathrm{MPa})$ & $A_{50}(\%)$ & $R_{p} / R_{m}(\%)$ \\
\hline 1 & 0 & 390 & 260 & 38.0 & 66.67 \\
2 & 20 & 527 & 427 & 17.0 & 81.02 \\
3 & 30 & 543 & 441 & 16.2 & 81.22 \\
4 & 35 & 584 & 478 & 13.6 & 81.85 \\
5 & 40 & 592 & 496 & 11.6 & 83.78 \\
6 & 50 & 594 & 516 & 9.2 & 86.87 \\
7 & 60 & 642 & 563 & 5.6 & 87.69 \\
8 & 70 & 646 & 562 & 6.0 & 87.00 \\
9 & 80 & 728 & 694 & 2.8 & 95.33 \\
10 & 85 & 725 & 700 & 2.8 & 96.55 \\
11 & 90 & 700 & 690 & 0.8 & 98.57 \\
\hline
\end{tabular}


TABle 3: Mechanical properties of the dual-phase treated steel.

\begin{tabular}{|c|c|c|c|c|c|c|c|c|c|c|}
\hline No. & $\varepsilon_{\mathrm{TR}}(\%)$ & $T_{\text {IA }}\left({ }^{\circ} \mathrm{C}\right)$ & $f_{M}(\%)$ & $F_{F}(\%)$ & $d_{F}(\mu \mathrm{m})$ & $d_{M}(\mu \mathrm{m})$ & $R_{m}(\mathrm{MPa})$ & $R_{p}(\mathrm{MPa})$ & $A_{50}(\%)$ & $R_{p} / R_{m}$ \\
\hline 1 & 50 & 740 & 19.1 & 80.9 & 18.9 & 3.7 & 513 & 341 & 18.0 & 0.66 \\
\hline 2 & 50 & 785 & 34.5 & 65.5 & 20.3 & 4.8 & 531 & 364 & 14.0 & 0.69 \\
\hline 3 & 50 & 830 & 61.0 & 39.0 & 17.2 & 7.9 & 696 & 459 & 12.0 & 0.66 \\
\hline 4 & 60 & 740 & 19.0 & 81.0 & 15.7 & 2.9 & 518 & 348 & 19.6 & 0.67 \\
\hline 5 & 60 & 785 & 35.0 & 65.0 & 18.1 & 3.6 & 645 & 421 & 17.5 & 0.65 \\
\hline 6 & 60 & 830 & 60.0 & 40.0 & 15.4 & 7.1 & 712 & 463 & 16.8 & 0.65 \\
\hline 7 & 70 & 740 & 19.5 & 80.5 & 11.5 & 2.2 & 523 & 351 & 22.0 & 0.67 \\
\hline 8 & 70 & 785 & 35.0 & 65.0 & 13.8 & 3.5 & 661 & 456 & 20.0 & 0.69 \\
\hline 9 & 70 & 830 & 61.0 & 39.0 & 12.3 & 4.1 & 738 & 522 & 17.0 & 0.71 \\
\hline
\end{tabular}

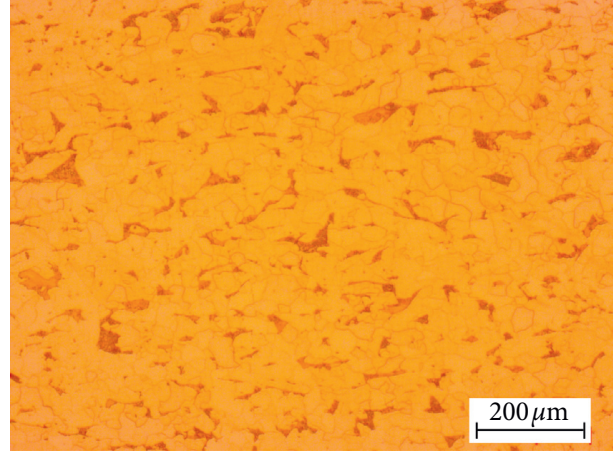

(a)

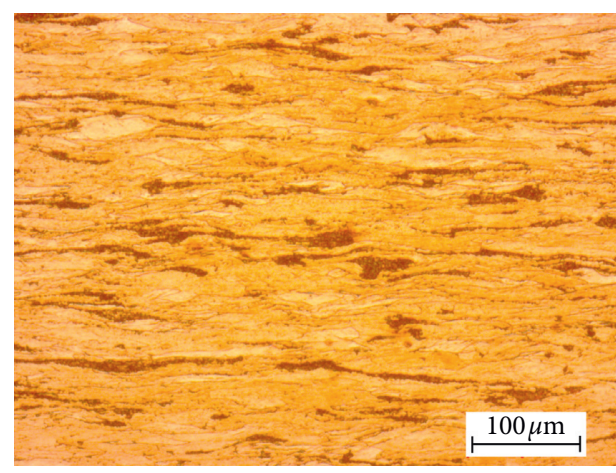

(c)

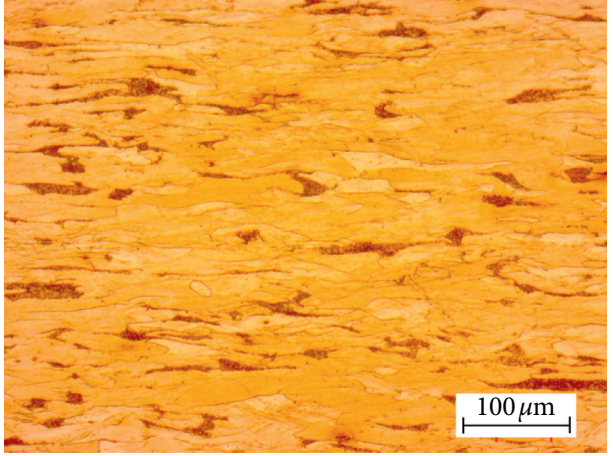

(b)

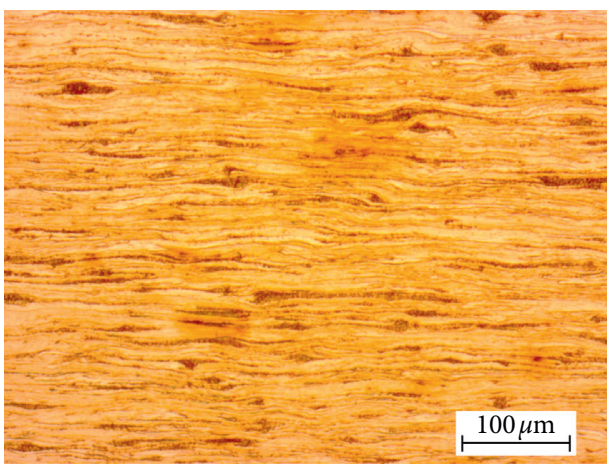

(d)

Figure 4: Microstructure of studied steel at different thickness reductions: (a) 0\%; (b) 50\%; (c) 60\%; (d) 70\%.

In order to evaluate the influential level of two processing factors on microstructure and mechanical properties of the dual-phase treated steel, the one-way ANOVA was used. Moreover, to consider visually the impact of these factors on microstructure and mechanical properties, the contour plots expressing their relationships were established by using the quadratic analysis and drawn by using the statistical software STATISTICA VERSION 10.

\section{Results and Discussion}

3.1. Effect of Deformation on Mechanical Properties of Studied Steel with Ferrite-Pearlite Microstructure. Figure 4(a)shows the ferrite-pearlite microstructure of the hot-rolled steel (before cold-rolling). It can be seen that the preparation process created a fine and equiaxial microstructure with pearlite grains regularly dispersed in a continuous ferrite matrix and ferrite grain size of about 20 to $25 \mu \mathrm{m}$. The rolled microstructure of this steel with several different thickness reductions is shown in Figure 4(b)-4(d). It was found that the more the thickness reduction increases, the longer the ferrite and pearlite grains are drawn. In general, increasing thickness reduction leads to an increase in the strength of cold-rolled steels.

Figure 5 shows the relationship between thickness reduction and mechanical properties. We can clearly see that both yield and ultimate tensile strengths are strongly increased followed by the increase in rolling deformation, but yield to tensile ratio is slightly increased and elongation is sacrificed significantly. Maximum ultimate tensile strength reached about $700 \mathrm{MPa}$ at thickness reduction of 80 to $90 \%$, but elongation is quite low under $3 \%$. For structural applications, this ductility is not proper for the fact. With a thickness reduction of 50 to $70 \%$, ultimate tensile strength is from 600 to $650 \mathrm{MPa}$ and elongation is over 5\%. This reduction could be used for actual applications. 


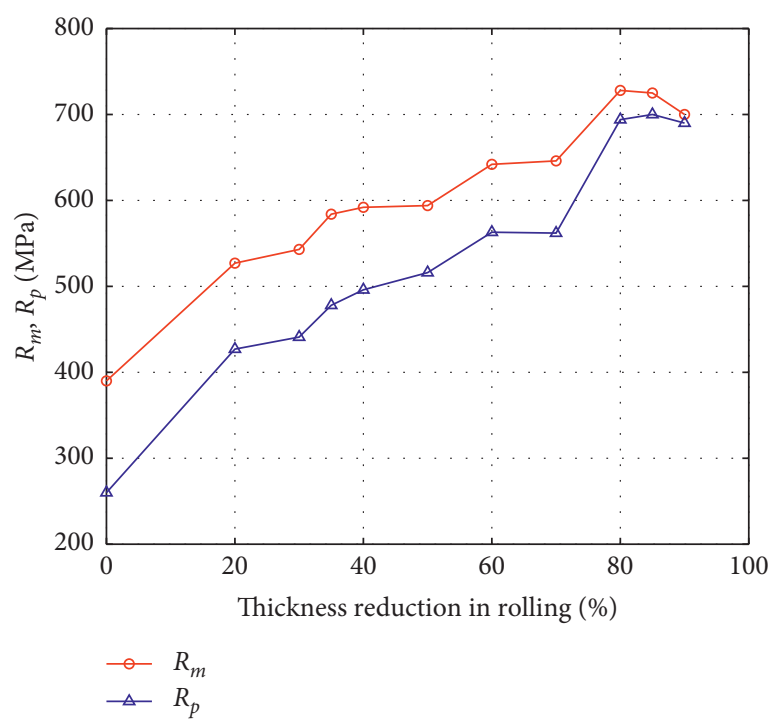

(a)

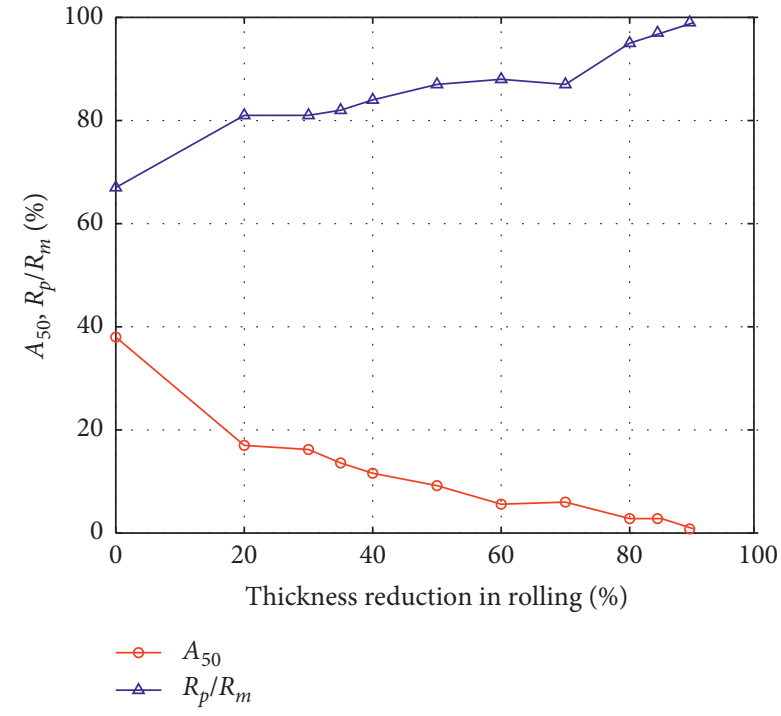

(b)

FIGURE 5: Effect of thickness reduction on mechanical properties.

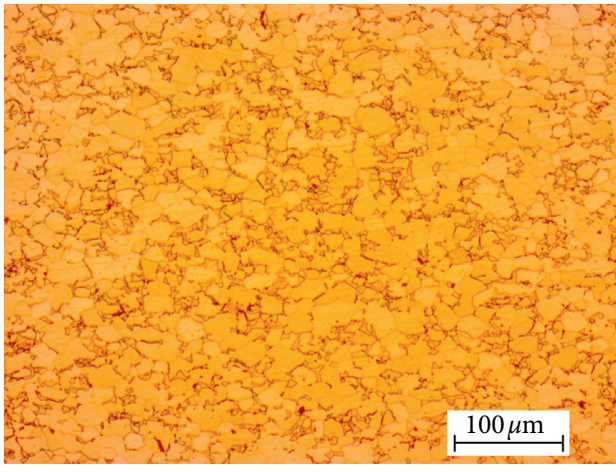

(a)

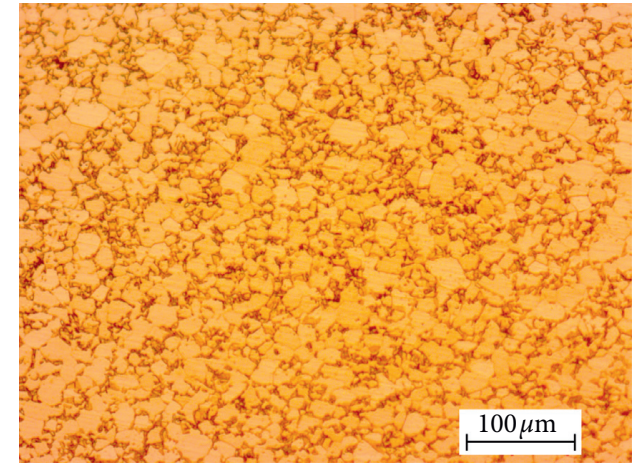

(b)

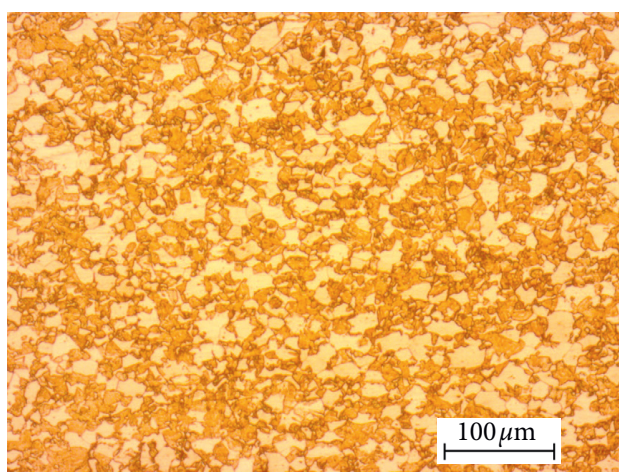

(c)

Figure 6: Microstructures of the steel at different temperatures with thickness reduction of $60 \%$ : (a) $740^{\circ} \mathrm{C}$; (b) $785^{\circ} \mathrm{C}$; (c) $830^{\circ} \mathrm{C}$.

\subsection{Effect of Deformation and Intercritical Annealing on Microstructure and Mechanical Properties of Studied Steel}

3.2.1. Effects on Microstructure. Figure 6 shows the microstructure of the dual-phase treated steel at three intercritical annealing temperatures of 740,785 , and $830^{\circ} \mathrm{C}$ with $60 \%$ in thickness reduction. As found on this figure, volume fraction and grain size of martensite depend on intercritical annealing temperatures. The increase in annealing temperature leads to increasing volume fraction of martensite and decreasing carbon content in it (Figure 7). The higher the annealing temperature is, the finer the grain size of martensite will be. Figure 8 shows contour plots expressing the relationships between grain 


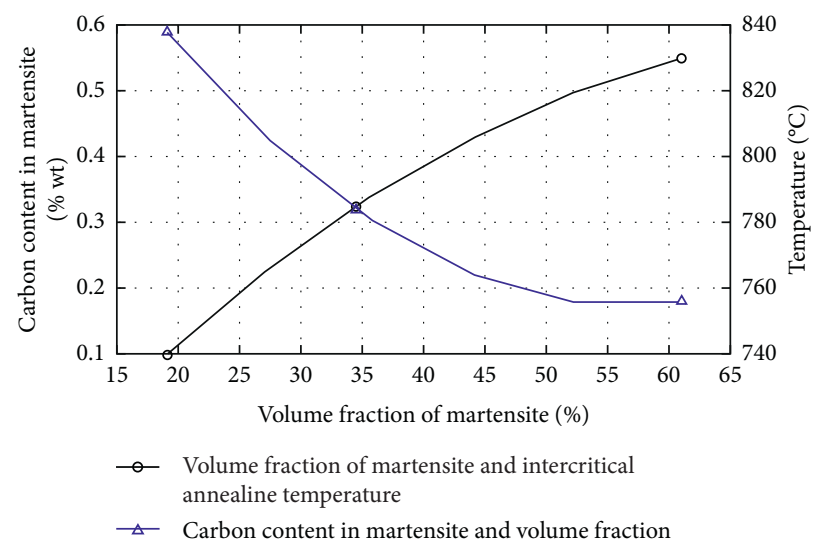

Figure 7: Dependence of volume fraction and carbon content of martensite on intercritical annealing temperature.

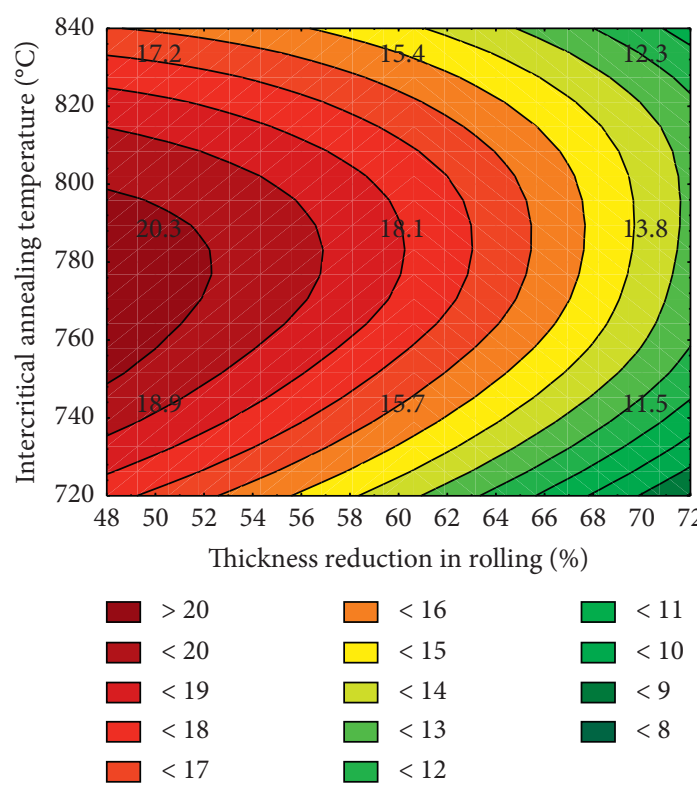

(a)

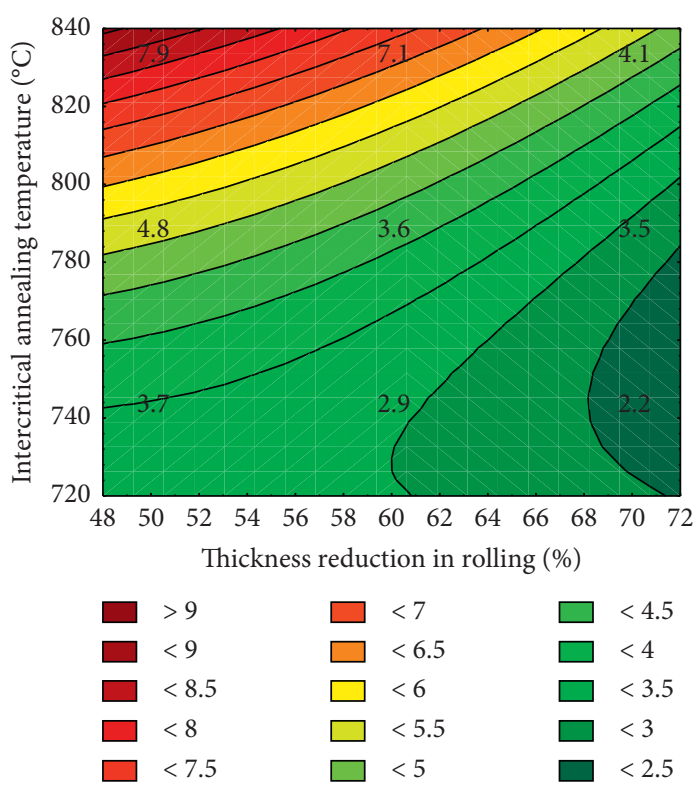

(b)

FIGURE 8: Effects of thickness reduction and annealing temperature on ferrite and martensite grain size: (a) ferrite; (b) martensite.

size of ferrite and martensite with thickness reduction and intercritical annealing temperature. Clearly, the thickness reduction increases more, while both grain sizes of ferrite and martensite reduce.

3.2.2. Effects on Mechanical Properties. The relations between mechanical properties and processing parameters are given in Figure 9. The statistically analyzed results for ultimate tensile strength (UTS), yield strength (YS), and elongation (El) are shown in Tables 4-6.

As known, the smaller the $P$-value is, the bigger the effect is. Thus, the data in the table ANOVA show that the annealing temperature has a stronger effect on UTS and YS than the deformation, while both of them have influence on El almost equally. These can be easily identified from Figure 9 through the position of contour lines.
Figure 9 shows that the increase in either annealing temperature or deformation leads to an increase in both UTS and YS, while the elongation is reduced with the increase in the annealing temperature and the decrease in deformation. It can be explained as follows; increasing the thickness reduction in rolling would increase the density of heterogeneous nucleation for recrystallizing when the steel is heated at intercritical annealing temperature range. As a result, many crystal grains will form, along with keeping the intercritical annealing time suitable; the phenomenon of grains merger has not occurred or occurred at a nonlarge level. The large number of grains per unit volume leads to reducing crystal grain size. According to Hall-Petch relation, the smaller the crystal grains are, the higher the strength will be. On the other hand, according to the general rule, increasing the annealing temperature leads to increasing the volume fraction of martensite (Figure 7); thus, dislocations- 


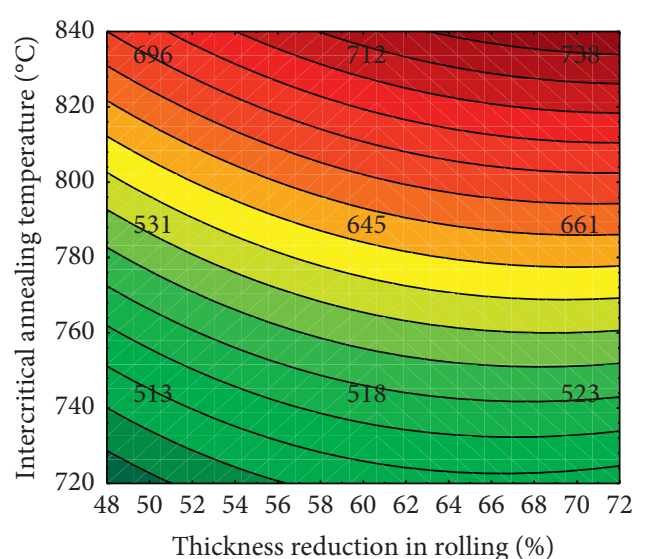

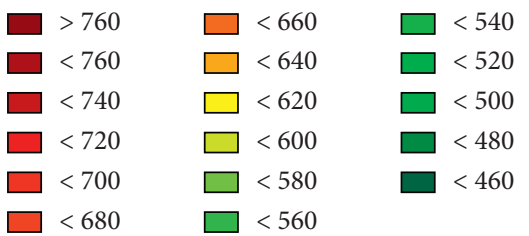

(a)
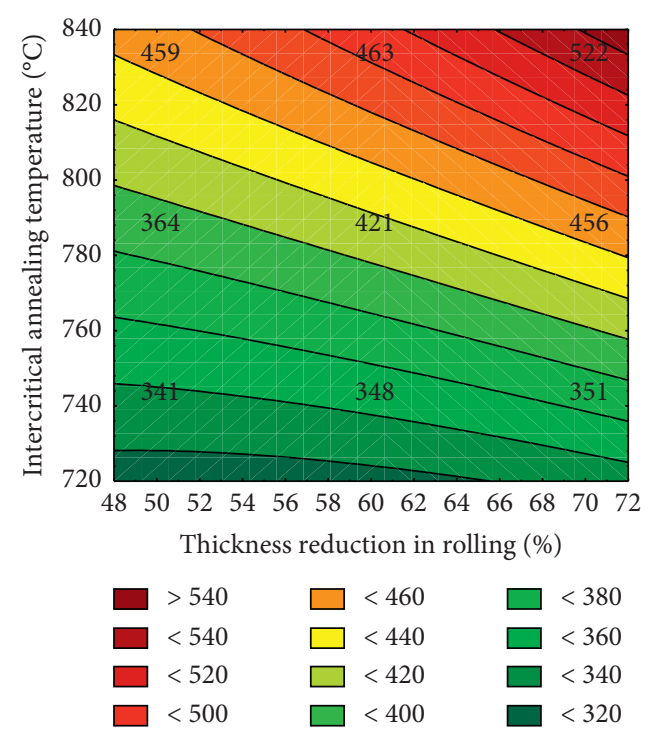

(b)

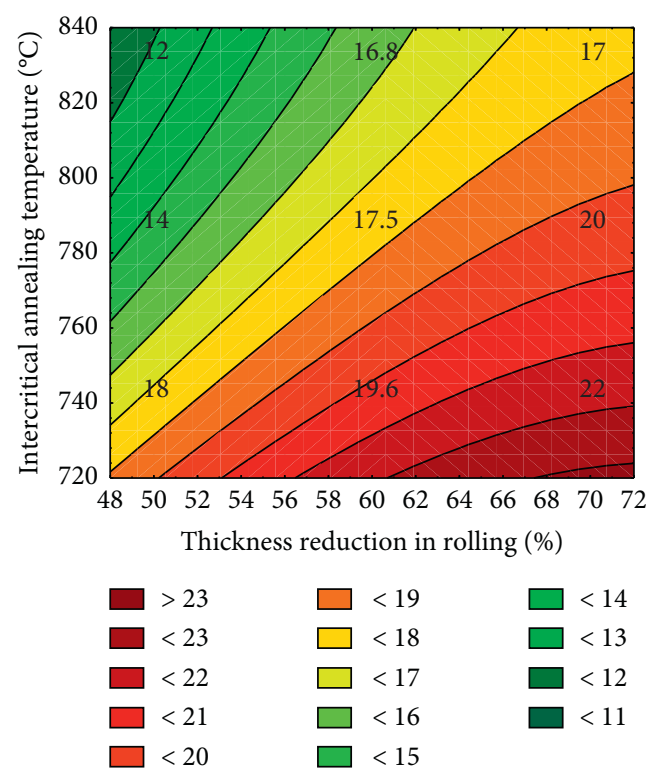

(c)

FIGURE 9: Effects of thickness reduction and intercritical annealing temperature on mechanical properties: (a) UTS; (b) YS; (c) El.

impeding agents would be enhanced, which cause the increase in pile-up of dislocations. This makes matrix phase increasingly hardened, which leads to an increase in strength.

Yield to tensile ratio of the dual-phase treated steel is almost constant, $0,68 \pm 0,03$. Thanks to this, forced structures can be safer and it also has more benefits for forming process.

3.2.3. Comparison of Mechanical Properties of the ColdRolled and Dual-Phase Treated Steel. Figure 10 expresses the relationship between tensile strength and elongation of the steel in the only cold-rolled and dual-phase treated state. It can be shown that the strength and combination of tensile strength and elongation of the dual-phase treated steel are more prominent than those of the only cold-rolled steel. Review data in Figures 5 and 8 show that the ultimate tensile strength of the dual-phase treated steel reaches $750 \mathrm{MPa}$, but the steel still has a good elongation, while that of the ferritepearlite microstructure steel is only up to about $700 \mathrm{MPa}$ with a significantly lower elongation and higher yield to tensile ratio.

Generally, dual-phase treatment of the studied low carbon steel brings a higher strength and better balance of strength and elongation compared to this steel in only coldrolled state. 
TABLE 4: ANOVA for ultimate tensile strength.

\begin{tabular}{|c|c|c|c|c|c|}
\hline Source & SS & $D F$ & $M S$ & $F$ & $P(>F)$ \\
\hline$\varepsilon_{\mathrm{TR}}$ & 5638 & 2 & 2819 & 1.2813 & 0.3715 \\
\hline$T_{\text {IA }}$ & 46031 & 2 & 23015 & 10.4610 & 0.0258 \\
\hline Error & 8800 & 4 & 2200 & & \\
\hline Total & 60470 & 8 & 7559 & & \\
\hline
\end{tabular}

TABLE 5: ANOVA for yield strength.

\begin{tabular}{|c|c|c|c|c|c|}
\hline Source & SS & $D F$ & $M S$ & $F$ & $P(>F)$ \\
\hline $\mathcal{E}_{\mathrm{TR}}$ & 5247 & 2 & 2623 & 2.4274 & 0.2041 \\
\hline$T_{\text {IA }}$ & 21930 & 2 & 10965 & 10.1453 & 0.0271 \\
\hline Error & 4323 & 4 & 1081 & & \\
\hline Total & 31500 & 8 & 3937 & & \\
\hline
\end{tabular}

TABLE 6: ANOVA for elongation.

\begin{tabular}{lcccc}
\hline Source & $S S$ & $D F$ & $M S$ & $F$ \\
\hline$\varepsilon_{\text {TR }}$ & 40 & 2 & 20 & 15.4291 \\
$T_{\text {IA }}$ & 29 & 2 & 15 & 11.3417 \\
Error & 5 & 4 & 1 & 0.0132 \\
Total & 74 & 8 & 9 & 0.0225 \\
\hline
\end{tabular}

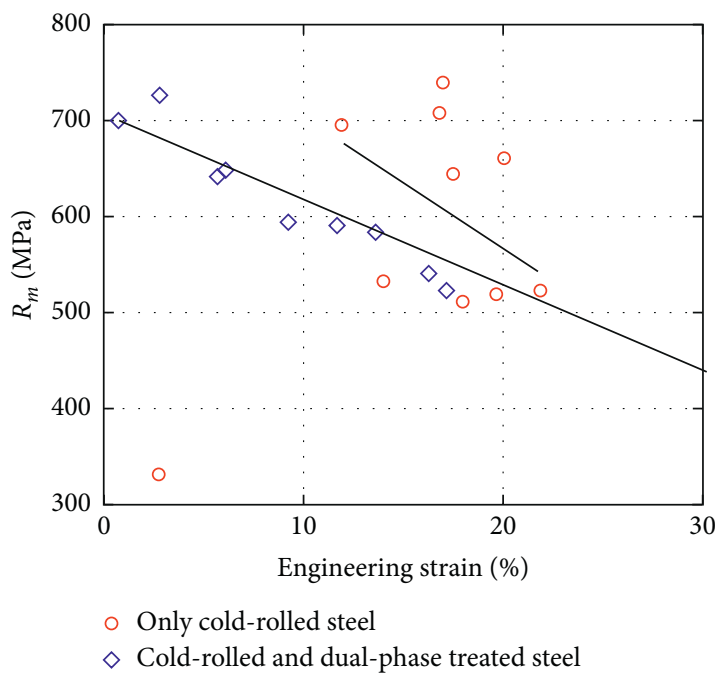

FIGURE 10: Comparison of combination of UTS and elongation of the cold-rolled and dual-phase treated steel.

\section{Conclusion}

The effects of rolling deformation on mechanical properties of the studied low carbon steel with ferrite-pearlite microstructure, as well as those of cold-rolling deformation and intercritical annealing temperature on mechanical properties of this steel, can be concluded as follows:

(i) In the normally cold-rolled condition, the ultimate tensile strength of the studied steel can reach $700 \mathrm{MPa}$ at thickness reduction of 80 to $90 \%$. The increase in strength leads to the sacrifice in ductility. For structural applications that require high strength to resist the load, the thickness reduction in rolling of about 60 to $70 \%$ can be chosen to receive the ultimate tensile strength of about 600 to $650 \mathrm{MPa}$.

(ii) The dual-phase treated-studied steel gets better compared to the only cold-rolled steel in the entire mechanical properties. Intercritical annealing temperature has an influence on ultimate tensile and yield strength stronger than rolling deformation, but is almost as equal as on elongation. The increase in both annealing temperature and deformation makes grain size of ferrite and martensite finer, which leads to improving both strength and ductility. Maximum tensile strength can reach $750 \mathrm{MPa}$ at the annealing temperature of $830^{\circ} \mathrm{C}$ and thickness reduction of $70 \%$.

(iii) The dominant point of this study is using the process of the dual-phase steel to improve the strength of the low carbon steel for structural applications. The most specific application that can be clearly visual is using this process at the final forming step of the thin wall cups made of the low carbon steel to receive higher strength of the finished products; thanks to that, they can undergo the higher pressure.

\section{Nomenclature}

$\mathcal{E}_{\mathrm{TR}}$ : Thickness reduction in rolling

$T_{\text {IA }}$ : Intercritical annealing temperature

$f_{F}$ : Volume fraction of ferrite

$f_{M}$ : Volume fraction of martensite

$d_{F}$ : Grain size of ferrite

$d_{M}$ : Grain size of martensite

$C_{\mathrm{M}}$ : Carbon content in martensite 
$\mathrm{C}_{0}$ : Carbon content in the initial steel

$R_{p}$ : Yield strength (YS)

$R_{m}$ : Ultimate tensile strength (UTS)

El: Elongation

$A_{50}$ : Elongation at fracture of tensile samples with gage

SS: Sequential sum of squares

DF: Degree of freedom

MS: Adjusted mean squares

$F: \quad F$-value in one-way ANOVA

$P: \quad P$-value (the probability of obtaining the observed results of a test).

\section{Data Availability}

Data used to support the findings of this study are included within the article.

\section{Conflicts of Interest}

The authors declare that they have no conflicts of interest.

\section{Acknowledgments}

The authors are deeply grateful to "Vietnam Mineral Resources and Metallurgy Joint Stock Company" for financing for our study via their National Project (2014 to 2019). The authors also express their profound gratitude to the Institute of Technology, General Department of Defense Industry, for supporting their experiments.

\section{References}

[1] A. R. Marder, "Deformation characteristics of dual-phase steels," Metallurgical Transactions A, vol. 13, no. 1, pp. 85-92, 1982.

[2] M. Mazinani and W. J. Poole, "Effect of martensite plasticity on the deformation behavior of a low-carbon dual-phase steel," Metallurgical and Materials Transactions A, vol. 38, no. 2, pp. 328-339, 2007.

[3] Y. Mazaheri, A. Kermanpur, and A. Najafizadeh, "Strengthening mechanisms of ultrafine grained dual phase steels developed by new thermomechanical processing," ISIJ International, vol. 55, no. 1, pp. 218-226, 2015.

[4] N. Fonstein, Advanced High Strength Sheet Steels: Physical Metallurgy, Design, Processing, and Properties, Springer International Publisher, Berlin, Germany, 2015.

[5] R. Rana and B. Singh, Automotive Steels: Design, Metallurgy, Processing and Applications, Woodhead Publishing, Cambridge, UK, 1 st edition, 2016.

[6] D. Budford, D. Matlock, and G. Krauss, "Effect of microstructural refinement on the deformation behavior of dualphase steels," in Strength of Metals and Alloys, vol. 1, pp. 189-194, Elsevier, Amsterdam, Netherlands, 1985.

[7] M. Alibeyki, H. Mirzadeh, and M. Najafi, "Fine-grained dual phase steel via intercritical annealing of cold-rolled martensite," Vacuum, vol. 155, pp. 147-152, 2018.

[8] D. Terada, G. Ikeda, P. Myeong-heom, A. Shibata, and N. Tsuji, "Reason for high strength and good ductility in dual phase steels composed of soft ferrite and hard martensite," IOP Conference Series: Materials Science and Engineering, vol. 219, 2017.
[9] A. Hüseyin, K. Z. Havva, and K. Ceylan, "Effect of intercritical annealing parameters on dual phase behavior of commercial low-alloyed steelsannealing parameters on dual phase behavior of commercial low-alloyed steels," Journal of Iron and Steel Research International, vol. 17, no. 4, pp. 73-78, 2010.

[10] M. Nouroozi, H. Mirzadeh, and M. Zamani, "Effect of microstructural refinement and intercritical annealing time on mechanical properties of high-formability dual phase steel," Materials Science and Engineering: A, vol. 736, pp. 22-26, 2018.

[11] A. Bayram, A. Uğuz, and M. Ula, "Effects of microstructure and notches on the mechanical properties of dual-phase steels," Materials Characterization, vol. 43, no. 4, pp. 259-269, 1999.

[12] S.-J. Kim, Y.-G. Cho, C.-S. Oh, D. E. Kim, M. B. Moon, and H. N. Han, "Development of a dual phase steel using orthogonal design method," Materials \& Design, vol. 30, no. 4, pp. 1251-1257, 2009.

[13] D. V. Hien, N. V. Chuc, T. N. Thanh, and S. M. Thang, "Influence of heat treatment on microstructure and mechanical properties of a CMnSi TRIP steel using design of experiment," Materials Today: Proceedings, vol. 5, no. 11, pp. 24664-24674, 2018. 